\title{
Chapter 6 \\ The Central Bank as Lender of Last Resort
}

In this chapter we review the function of the central bank as lender of last resort (LOLR), starting from the understanding of financial crises developed in the previous chapter. We recall long-established LOLR principles: proactive lending, inertia of the central bank risk control framework, and risk endogeneity. Because of its systemic role, a central bank should not tighten its collateral framework in a crisis, as restrictive policies are likely to not only increase the overall damage done by a crisis to society, but to even increase central bank losses. We explain in more detail the main reasons why a central bank should act as LOLR: prevent negative externalities from fire sales; its unique status as institution with unlimited liquidity; its status as a risk-free counterparty making others accept to deliver collateral to it even at high haircuts; and its mandate to preserve price stability. We distinguish three different forms of LOLR: elements built into the regular operational framework; readiness to relax parameters in a crisis; and provision of emergency liquidity assistance to individual firms. We then discuss what could be the optimal propensity of a central bank to engage in LOLR activities and outline possible trade-offs. Last but not least, we develop a bank-run model which highlights the role of asset liquidity and central bank eligible collateral. We calculate through a model variant with binary asset liquidity and uniform central bank collateral haircut, but then also introduce a model variant with continuous asset liquidity and haircuts. 


\subsection{Principles and Rationale for the Central Bank Acting as Lender of Last Resort}

\subsubsection{Origin and Principles of LOLR}

While large-scale and successful LOLR measures of central banks can be traced back to at least 1763 (e.g. Bindseil 2019), today's thinking on the LOLR function is still strongly inspired by nineteenth century experience, and in particular Walter Bagehot's Lombard Street of 1873 (see also e.g. Goodhart 1999; Goodhart and Illing 2002). Consider three key insights of nineteenth century experience which still appear valid today.

Lend pro-actively while preserving the safety of the central bank. In a hearing of the Lords' Committee in 1832, Bank of England director Jeremiah Harman summarised the Bank's actions in the panic of 1825 as follows (see Bagehot 1873):

We lent... by every possible means, and in modes that we never had adopted before; we took in stock of security, we purchased Exchequer bills, we made advances on Exchequer bills, we not only discounted outright, but we made advances on deposits of bills to an immense amount; in short, by every possible means consistent with the safety of the Bank;... seeing the dreadful state in which the public were, we rendered every assistance in our power.

Harman presents the Bank of England's action as having been creative and proactive, i.e. to have innovated to find the best ways to support funding liquidity of financial institutions, the only constraint to creativity being the need to preserve the "safety of the Bank", i.e. limit additional risk taking.

Inertia of risk control framework. Bagehot (1873) himself advises the Bank of England that, in a crisis, it should maintain its risk control framework broadly unchanged, and not tighten it similarly to private lenders as a reaction to a worsened asset quality and liquidity, as well as higher volatility, etc.:

If it is known that the Bank of England is freely advancing on what in ordinary times is reckoned a good security and on what is then commonly pledged and easily convertible, the alarm of the solvent merchants and bankers will be stayed. But if securities, really good and usually convertible, are refused by the Bank, the alarm will not abate, the other loans made will fail in obtaining their end, and the panic will become worse and worse.

Bagehot refers to various episodes in which the Bank of England did not follow this principle and ended up making the crisis worse than it would have needed to be.

Risk Endogeneity. Bagehot argues that supportive liquidity provision could be necessary to minimize the Bank of England's eventual own financial risks, because it would be the only way to prevent a financial meltdown with unavoidable large losses also for the Bank of England: 
(M)aking no loans as we have seen will ruin it (Bank of England); making large loans and stopping, as we have also seen, will ruin it. The only safe plan for the Bank is the brave plan, to lend in a panic on every kind of current security, or every sort on which money is ordinarily and usually lent. This policy may not save the Bank; but if it does not, nothing will save it.

In other words, the riskiness of exposures would itself be endogenous to the central bank measures. Liberal central bank lending could imply lower central bank financial risk taking than tight risk controls, turning upside down the logic of private lenders.

\subsubsection{Why Should Central Banks Be Lenders of Last Resort?}

We identify five reasons for a central bank to act as lender of last resort in a financial crisis.

\subsubsection{Negative Externalities of Funding Liquidity Stress}

Public authorities may intervene in markets in case of negative externalities. A major negative externality of bank stress relates to the fire sale spiral induced by liquidity problems of individual banks. If banks are forced to sell assets to generate liquidity, these sales likely depress market prices. In turn, this generates renewed solvency and liquidity stress for banks, possibly triggering further fire sales, etc. Central bank loans which reduce the need for asset fire sales can prevent such a downward spiral. Asset fire sales are not the only form of negative externalities of bank funding stress and illiquidity-induced default. Other negative externalities are, for example, the contagion of depositors' fears if they observe a bank run, possibly leading to further bank runs such as observed in the early 1930s.

\subsubsection{Central Banks Have Unlimited Liquidity (in a Paper Standard)}

Unlike leveraged private entities, a central bank is not threatened by illiquidity in the currency it issues. Modern central banks are endowed with the monopoly and freedom to issue legal tender. It is therefore opportune that, in case of a liquidity crisis when all financial and non-financial institution tend to hoard liquidity, central banks remain willing to lend and to hold illiquid assets outright or as collateral. This is unrelated to negative externalities, and even if a central bank were purely profitoriented, its unique access to liquidity justifies lending and purchases of illiquid assets in a crisis. 


\subsubsection{Haircuts Are a Particularly Effective Risk Mitigation Tool for Central Banks}

Haircuts are an effective tool if the collateral provider is more credit risky than the cash investor. In contrast, haircuts are less effective if cash provider and collateral provider are equally credit risky since the implied protection of the cash provider is at the expense of the collateral provider (Ewerhart and Tapking 2008). Therefore, simply increasing haircuts in symmetric interbank repo markets is not an adequate solution to provide more risk protection, while it is for asymmetric relationships, such as the one between a prime bank lending to a hedge fund. From the perspective of the collateral provider, a central bank is a risk-free counterparty as it cannot default and will always return pledged collateral. Central bank credit against illiquid collateral can be well-protected through high haircuts, without the collateral provider feeling unduly exposed. Against any other cash provider, i.e. against any credit risky cash provider, the collateral provider would likely be unwilling to accept the exposure implied by high haircuts.

\subsubsection{Central Banks May Have Superior Information}

A central bank may have, as bank supervisor, better information on the credit worthiness of banks in need of liquidity, compared with other market participants. Moreover, as a public entity not competing with banks, banks may be willing anyway to share private information with a central bank to establish their creditworthiness. In contrast, banks may be unwilling to reveal private information to competitors or private investors, even if this is made a pre-condition to obtaining funding from them. This may be particularly relevant when decisions need to be taken urgently.

\subsubsection{LOLR as an Unconventional Monetary Policy at the ZLB}

Taking LOLR measures may be decisive for a central bank to achieve its mandate to maintain price stability and to prevent the economy from falling into a deflationary trap. LOLR measures can prevent bank intermediation spreads from increasing in a crisis situation, which may be essential from a monetary policy perspective if the central bank has exhausted conventional monetary policy because of the zero lower bound (ZLB) on interest rates. This will be illustrated further by the model in Sect. 6.3. 


\subsection{Forms and Propensity to Act as LOLR}

\subsubsection{Forms of LOLR}

The central bank LOLR function can take three forms: (a) LOLR built into the regular operational framework of the central bank; (b) LOLR added through changes of the framework and additional LOLR operations for all banks in crisis times; (c) emergency liquidity assistance to individual banks or, more rarely, even to non-banks. We consider these three one after the other.

\section{LOLR built into the regular operational framework}

The following elements determine the LOLR content of the regular operational framework.

- As mentioned earlier, collateral availability provides a first natural limit to central bank credit at the individual bank level. The volume of eligible collateral should also be viewed in relation to the liquidity deficit of the banking system to be covered by central bank credit operations. For example, in the case of the Eurosystem, the nominal value of eligible marketable assets has had a value of around EUR 14 trillion since 2012 (ECB 2020b), of which around EUR 5 trillion is held by banks, against a (pre-crisis, i.e. pre-2008) EUR 0.5 trillion liquidity deficit of the euro area banking system to be covered by credit operations. This implies that an average representative bank could extend, before hitting collateral constraints, recourse to central bank credit approximately 10 times relative to proportionality.

- The ease at which central bank credit can be accessed. In credit open market, the so-called "fixed-rate full allotment" procedure ensures that banks always get what they bid for. In a competitive auction, banks run a risk to not receive credit if they underestimate the aggressiveness with which other auction participants are bidding.

- Active stigmatisation or de-stigmatisation through central bank communication will impact on the propensity of banks to rely on the LOLR.

- It matters who is able to access central bank credit and benefit directly from the LOLR. Normally, only commercial banks have access to central bank credit, i.e. neither non-bank financials, nor non-financial corporates have.

\section{Readiness of central banks to add LOLR content to the operational framework in crisis times}

The impact of the LOLR on bank behaviour will not be limited to the LOLR content of the operational framework in normal times. What matters as well is the bank's liquidity in a scenario of financial market stress. Anticipating this case also includes building expectations on the readiness of the central bank to adjust the abovementioned parameters that determine the LOLR content of the operational framework. Expectations will be determined by historical experience and forward-looking central bank communication. 


\section{Readiness of central banks to provide emergency liquidity assistance (ELA) to individual banks}

ELA can be defined as a non-rule based LOLR activity for the benefit of individual banks. Of course, ELA also needs to take place within some legal framework, within the mandate of the central bank and ideally in a consistent manner. Limitations to ELA provision can result from:

(i) ELA collateral requirements (normally ELA collateral sets should be wider than the standard collateral set). (ii) Pricing of ELA, i.e. what surcharge relative to monetary policy credit operations is imposed (some surcharge is typically applied). (iii) Relevance to preserve systemic financial stability may be a precondition for granting ELA. The higher the hurdle set by the central bank in declaring a systemic financial stability interest before granting ELA, the less a bank can rely ex-ante on it, in particular if a bank is small. (iv) Limitations on the duration of ELA (ELA is typically assumed to be of limited duration). (v) Possible requirement that ELA is only granted if the central bank is protected in addition by a government guarantee. Beyond additional risk protection, this may be considered useful as it requires an elected government to confirm its backing of ELA operations (but it should not delay very urgent and obvious ELA provision by the central bank). (vi) ELA counterparty set: While normal central bank credit is only granted to banks, ELA could also be granted to any other financial corporate (or in theory even to any debtor).

\subsubsection{Overall Propensity of a Central Bank to Act as LOLR}

It is conceptually useful to first consider two extreme LOLR choices of the central bank.

- Maximum LOLR: accept in the normal-times operational framework all assets of banks as collateral at fair values without haircut. This would allow solvent banks to finance all their assets with the central bank, if desired, and no solvent counterparty could ever default for liquidity reasons. Furthermore, central bank credit is provided at a high frequency through fixed rate full allotment operations at the monetary policy target interest rate.

- Minimum LOLR: the central bank implements monetary policy only against riskfree assets, say AAA-rated Government paper. It largely covers its asset side through outright holdings of these AAA assets, and only conducts at the margin repos against the same assets. It conducts these small repos only with the highest rated counterparties. In this operational framework, banks have no discretionary access to central bank credit at all, i.e. the operational framework has no LOLR element. Moreover, the central bank would fully pre-commit to never change the LOLR content of its operational framework nor to ever provide ELA.

Central bankers believe that the optimal LOLR is in between these two extremes. The LOLR strengthens the ability of the financial system to provide maturity and liquidity transformation as services to society. At the same time, putting some limits 
to the LOLR role is beneficial for society, to have some protection against information asymmetries and moral hazard, to avoid relying excessively on the abilities of supervisors and auditors, and generally to preserve stronger incentives to maintain funding market access and thereby market discipline. Proponents of a tight approach may argue that a supportive LOLR will lead to as many financial crises as a very tight one, but crisis will be messier because when they occur the financial leverage will be much higher ("four-wheel vehicles make you get stuck in areas which are more difficult to access when you need to be rescued").

Assume for a moment that we capture in the unit interval $[0,1]$ the supportiveness of the LOLR framework of a central bank and let the most restrictive framework described above be represented by 0 and the most forthcoming framework by 1 (it is of course a simplification to assume that designing the LOLR framework is a one-dimensional problem). One can map the LOLR unit interval into at least five effects, which should not be expected to be identical, although often this seems to be implicitly assumed:

(1) Social welfare is the ultimate measure of interest and can be equated, for example, with the extent to which the LOLR framework contributes to financial conditions leading to maximum economic growth in the medium to long term, i.e. through the financial and economic cycle. For example, Keister (2016) maps the LOLR supportiveness into social welfare, and Bindseil and Jablecki (2013) map it into growth. They show that it is likely that the relationship is a concave function with interior maximum (i.e. an intermediate LOLR maximizes growth).

(2) Risk taking is normally expected to increase monotonously for normal lenders when the readiness and ease of lending increases. For central banks, risk taking may be non-monotonous in the LOLR unit interval [0,1]. Bindseil and Jablecki (2013) provide an example in which the relationship is a convex function with interior minimum. As Bagehot's insight that sometimes "only the brave plan is the safe plan" suggests, the central bank cannot base its LOLR choices on the basis of the risk considerations that would apply for an "atomistic" investor not influencing the properties (e.g. default probabilities) of the system. Often, being more forthcoming as an LOLR after a negative financial stability shock (e.g. broadening the eligible collateral set to include less liquid assets) will decrease financial risk taking by the central bank, instead of increasing it. Risk endogeneity should lead to a more forthcoming LOLR, i.e. the welfare maximizing LOLR framework will be more supportive than the one obtained if risk endogeneity is ignored.

(3) Leverage of banks and their ability to provide liquidity and maturity transformation should increase monotonously with the supportiveness of the LOLR. Regulation may limit leverage to lower levels.

(4) Financial fragility will probably first decrease, and then increase across the LOLR unit interval, suggesting that a measured LOLR can stabilize the financial system while a too liberal one could eventually lead to particularly deep financial crises. 
(5) Market discipline and funding market functioning can be thought of as either falling monotonously, or as mirroring the financial fragility curve, i.e. it would benefit from some moderate LOLR, but is undermined if the LOLR is excessive. Section 6.5 shows that when asset liquidity deteriorates after an exogenous shock, then the LOLR can preserve funding market access for solvent banks, but not for insolvent banks, while a restrictive LOLR will imply a run also on solvent banks. In this sense a more supportive LOLR can allow for a more effective market mechanism than a very restrictive one.

\section{Moral hazard and central bank losses}

A popular theme in papers on the LOLR is moral hazard, but the concept often remains vague. One pragmatic view is that moral hazard only materializes in the context of the LOLR if the central bank faces actual losses from its credit operations. This interpretation also has the advantage that it would reduce the complexity of the LOLR design problem by one dimension and map something vague and complex (moral hazard) into something concrete and more measurable (central bank risk taking-even if complicated by endogeneity). If central banks are worried about moral hazard, they could tighten risk control measures (in normal times, to not be pro-cyclical) so that the probability of central bank credit losses declines even further.

\section{Excessive stigmatization of the LOLR?}

Sometimes central banks worry that banks attach excessive stigma to recourse to the LOLR. For example, recourse to the Discount Window is considered to remain stigmatized in the US although the Fed has wanted to change this since 2002 (Armantier et al. 2015). Also, in a number of credit open market operations of central banks during the financial crisis, aversion of banks to participate materialized so that the accommodation that the operations aimed at could not be achieved. Excessive stigmatization seems to go in the opposite direction of moral hazard. Central banks should therefore have tools in hand to adjust in both directions the willingness of banks to come to LOLR operations.

\subsection{Central Bank Collateral as a Key LOLR Parameter in a Simple Bank Run Model}

In this section we will integrate the LOLR in a bank-run model. In Sect. 6.3.1 we will introduce a bank-run model in which a bank owns two kinds of assets, a completely liquid asset and a completely illiquid asset. In Sect. 6.3.2, asset liquidity will be described by means of a power function, which allows additional insights. 


\subsubsection{A Bank Run Model with Binary Levels of Asset Liquidity}

Throughout this section, we consider the stylized bank balance sheet in Table 6.1. The total length of the balance sheet has been set to unity. Assets are grouped into two homogeneous classes in terms of asset liquidity and fire-sale discounts $(\Lambda \in[0,1])$. There are three types of liabilities, equity, long-term debt, and short-term deposits (with $\mathrm{e} \in[0,1], \mathrm{t} \in[0,1]$ and $\mathrm{d} \in[0,0.5])$.

The stylized balance sheet is sufficient to capture one key issue of banking: how to ensure the confidence of short-term depositors of the bank such that they do not easily withdraw deposits because of perceived credit risk, triggering self-fulfilling destructive dynamics ending in bank default. Confidence can be sustained by two means. First, the bank may limit the role of short-term funding. However, in general, households and institutional investors prefer to hold short-term debt instruments over long-term debt instruments and equity and request a higher return rate on the latter two types of claims, so that long-term debt and capital is associated with higher funding costs for the bank. Second, the bank may aim at holding sufficient amounts of liquid assets, both in the sense of being able to liquidate these assets in case of need, and to pledge them with the central bank at favourable haircuts. However, on average, liquid assets generate lower returns than illiquid ones. We now consider the representative bank in more detail.

\subsubsection{Asset Liquidity and Central Bank Collateral Treatment}

Assume two types of assets with extreme liquidity properties:

- A share $\Lambda(0 \leq \Lambda \leq 1)$ of assets is fully liquid and can be sold without any fire-sale losses.

- A share $1-\Lambda$ of assets is totally illiquid, i.e. if one tried to fire-sell these assets, one would not generate a cent of liquidity, but only losses.

At the same time, it is assumed that, when accepting bank assets as collateral, the central bank applies a homogeneous haircut $h$ on all assets. In other words, the central bank haircut and collateral framework is not sensitive at all to asset liquidity.

Table 6.1 A stylised bank balance sheet to analyse funding stability of a bank

\begin{tabular}{|c|c|c|c|}
\hline \multicolumn{4}{|c|}{ Bank } \\
\hline Liquid assets & $\Lambda$ & Short-term debt 1 & $\mathrm{~d}$ \\
\hline \multirow[t]{3}{*}{ Illiquid assets } & $1-\Lambda$ & Short-term debt 2 & $\mathrm{~d}$ \\
\hline & & Long-term debt (term funding) & $\mathrm{t}$ \\
\hline & & Equity & $\mathrm{e}$ \\
\hline Total assets & 1 & Total liabilities & 1 \\
\hline
\end{tabular}




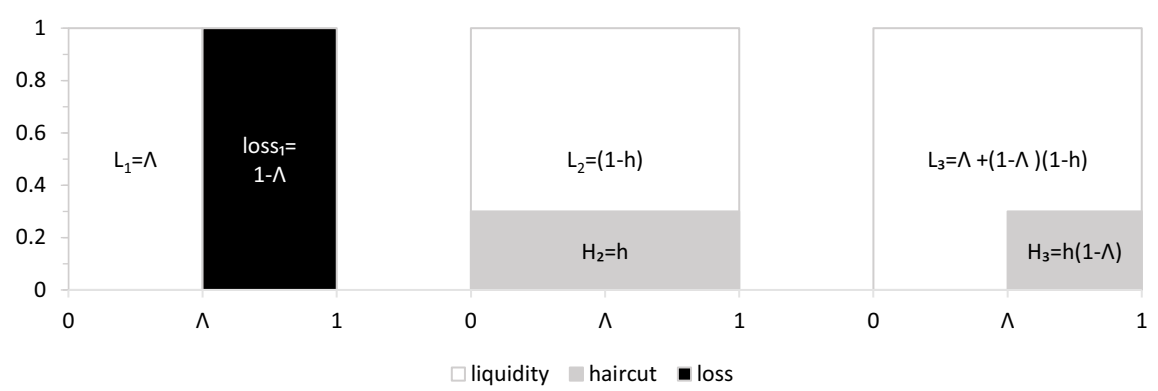

Fig. 6.1 Liquidity generation in a binary level of liquidity. Left: by liquidating all assets. Centre: by pledging all assets with the central bank. Right: liquidity-maximising combination

We summarise these assumptions in Fig. 6.1. Obviously in this case it never makes sense to fire-sell the illiquid assets as this would generate no liquidity but maximum losses. The illiquid assets should instead be pledged with the central bank. At the same time, to generate maximum liquidity, it makes sense to sell the liquid assets and to not pledge them.

\subsubsection{Bank Liabilities}

There are four types of liabilities: (i) Short-term liabilities are equally split to two ex-ante identical depositors; (ii) Long-term debt does not mature within the period considered and is ranked pari passu with short-term debt in case of liquidation of the bank; (iii) Equity is junior to all other liabilities and is also a stable funding source; (iv) Central bank borrowing is zero initially but can substitute for outflows of short-term liabilities in case of need.

\subsubsection{Timeline}

The model is based on the following timeline:

1. The asset parameters $h$ and $\Lambda$ are given

2. The bank chooses its liability composition, i.e. the parameters $\mathrm{d}$ and e.

3. Short-term depositors play a strategic game with two alternative actions: to run or not to run. "Running" means withdrawing deposits and transferring them to another account, accepting a small transaction $\operatorname{cost} \varepsilon$.

4. It is not to be taken for granted that depositors can withdraw all their funds. If one or both of the depositors run, then at least one or several of the following will apply:

(i) The bank substitutes lost deposit with central bank credit, assuming the bank has sufficient eligible collateral. 
(ii) Liquidation of assets: the bank may sell assets (but only when liquidation values exceed collateral values after haircuts).

(iii) If it is impossible to pay out the depositors that want to withdraw their deposits, illiquidity induced default occurs. After full liquidation took place, remaining depositors are paid out pari passu.

5. If the bank was not closed due to illiquidity in the previous stage, its solvency is assessed by the supervisor. If capital is negative, the bank is liquidated and it is assumed in this case that the full costs of immediately liquidating all assets materialize. If it is still solvent, the bank survives.

\subsubsection{Equilibrium}

We use a Strict Nash No-Run (SNNR) equilibrium concept. The decision set of depositor $i(i=1,2)$ from which he will choose his decision $D_{i}$ is $\left\{K_{i}, R_{i}\right\}$, where " $K$ " stands for "keeping" deposits and "R" stands for "run". The payoff function of depositor $\mathrm{i}$ is: $\mathrm{U}_{\mathrm{i}}=\mathrm{U}_{\mathrm{i}}\left(\mathrm{D}_{1}, \mathrm{D}_{2}\right)$. The strategic game is symmetric, i.e. $\mathrm{U}_{1}\left(\mathrm{~K}_{1}, \mathrm{~K}_{2}\right)=\mathrm{U}_{2}\left(\mathrm{~K}_{1}\right.$, $\left.\mathrm{K}_{2}\right), \mathrm{U}_{1}\left(\mathrm{~K}_{1}, \mathrm{R}_{2}\right)=\mathrm{U}_{2}\left(\mathrm{R}_{1}, \mathrm{~K}_{2}\right), \mathrm{U}_{1}\left(\mathrm{R}_{1}, \mathrm{~K}_{2}\right)=\mathrm{U}_{2}\left(\mathrm{~K}_{1}, \mathrm{R}_{2}\right), \mathrm{U}_{1}\left(\mathrm{R}_{1}, \mathrm{R}_{2}\right)=\mathrm{U}_{2}\left(\mathrm{R}_{1}, \mathrm{R}_{2}\right)$. This allows us to express in the rest of the model conditions only with reference to one of the two players, say depositor 1 .

A Strict Nash equilibrium is defined as a strategic game in which each player has a unique best response to the other players' strategies (see Fudenberg and Tirole 1991, 11). A Strict Nash No-Run (SNNR) equilibrium in the run game is therefore one in which the "no-run" choice dominates the "run" choice regardless of what the other depositors decide, i.e. an SNNR equilibrium is defined by:

$$
\mathrm{U}_{1}\left(\mathrm{~K}_{1}, \mathrm{~K}_{2}\right)>\mathrm{U}_{1}\left(\mathrm{R}_{1}, \mathrm{~K}_{2}\right) \cap \mathrm{U}_{1}\left(\mathrm{~K}_{1}, \mathrm{R}_{2}\right)>\mathrm{U}_{1}\left(\mathrm{R}_{1}, \mathrm{R}_{2}\right)
$$

A strict run equilibrium applies if $\mathrm{U}_{1}\left(\mathrm{R}_{1}, \mathrm{~K}_{2}\right)>\mathrm{U}_{1}\left(\mathrm{~K}_{1}, \mathrm{~K}_{2}\right) \cap \mathrm{U}_{1}\left(\mathrm{R}_{1}, \mathrm{R}_{2}\right)>\mathrm{U}_{1}\left(\mathrm{~K}_{1}\right.$, $\left.\mathrm{R}_{2}\right)$, and a multiple equilibrium case arises if $\mathrm{U}_{1}\left(\mathrm{~K}_{1}, \mathrm{~K}_{2}\right)>\mathrm{U}_{1}\left(\mathrm{R}_{1}, \mathrm{~K}_{2}\right) \cap \mathrm{U}_{1}\left(\mathrm{R}_{1}, \mathrm{R}_{2}\right)$ $>\mathrm{U}_{1}\left(\mathrm{~K}_{1}, \mathrm{R}_{2}\right)$.

To identify the cheapest sustainable funding structure, we now define as a liquidity-stress strategy (LSS) of a bank a mapping of the assets of the bank into either their use as fire-sale reserves or as collateral for recourse to the central bank. In the chosen simple case, the choice of the LSS is trivial for the bank: liquid assets should be fire-sold, and illiquid assets should be pledged as collateral. This keeps liquidity generation capacity at a maximum and fire- sale losses at the minimum (zero). It is shown below that an SNNR applies if the liquidity generating power of the bank assets is at least equal to the deposits of one depositor, and equity is non-negative:

$$
\mathrm{L}=\Lambda+(1-\Lambda)(1-\mathrm{h}) \geq \mathrm{d} \text { and } \mathrm{e} \geq 0
$$

There are two possible states for solvency: either e $\geq 0$ (the bank is solvent), or e $<0$ (the bank is insolvent). The liquidity condition can be divided into three 
cases: either liquidity is enough to pay out both depositors, or only one depositor, or neither. Table 6.2 shows the depositor's equilibrium decision for the resulting six cases (because of symmetry it is the same for both players).

If equity is negative, run is always the equilibrium choice. If equity is positive a no-run equilibrium can be ensured if liquidity is sufficient to pay out one depositor. In establishing the payoffs in case of liquidation, we take a simplifying assumption, namely that the central bank, liquidating the assets pledged by the bank after default, recovers exactly the liquidity it had provided through the pledge, while the security buffer granted by the haircut is completely depleted, i.e. equal to $L=\Lambda+(1-\Lambda)(1-$ h). Under this assumption payoffs can be calculated in scenarios of liquidity-induced defaults by just taking the pay-outs before the moment of default.

\subsubsection{Positive Equity}

First, we analyse cases (1) to (3), in which equity is positive.

(1) Table 6.3 shows the precise pay-offs if there is enough liquidity to pay out both depositors, keeping is a superior strategy whatever the other depositor does, as it allows us to save $\varepsilon$, the cost of running (Table 6.3).

(2) If liquidity is sufficient for paying out only one depositor, i.e. $\mathrm{d} \leq \mathrm{L}<2 \mathrm{~d}$, the bank run game takes the payoffs as shown in Table 6.4.

That $\left(\mathrm{K}_{1}, \mathrm{~K}_{2}\right)$ is the unique solution for both cases can be shown by directly applying the definition of the SNNR equilibrium. In the second case, in the hypothetical case that both depositors ran (which they should not), the bank balance sheet would look as in Table 6.5 at the moment of default. The bank will have fire-sold all its liquid assets, and pledged all its non-liquid assets. The assumption that the central bank will "consume" the haircut when liquidating the asset implies that the losses in collateral liquidation will exceed and consume the previous equity of the bank.

Table 6.2 Equilibrium decision of depositors depending on liquidity and solvency of the bank

\begin{tabular}{l|l|l|l}
\hline \multicolumn{2}{c}{} & \multicolumn{2}{l}{ Solvency condition } \\
\cline { 3 - 4 } & e $\geq 0$ & $\mathrm{e}<0$ \\
\hline \multirow{2}{*}{ Liquidity condition } & $\mathrm{L} \geq 2 \mathrm{~d}$ & (1) keep & (4) run \\
\cline { 2 - 4 } & $\mathrm{d} \leq \mathrm{L} \leq 2 \mathrm{~d}$ & (2) keep & (5) run \\
\cline { 2 - 4 } & $\mathrm{L}<\mathrm{d}$ & (3) keep/run & (6) run \\
\hline
\end{tabular}

Table 6.3 Pay-offs to depositors if $\mathrm{L} \geq 2 \mathrm{~d}$ and $\mathrm{e} \geq 0$

\begin{tabular}{l|l|l}
\hline$\downarrow D_{1}, D_{2} \rightarrow$ & $K_{2}$ & $R_{2}$ \\
\hline$K_{1}$ & d, d & $d, d-\varepsilon$ \\
\hline$R_{1}$ & $d-\varepsilon, d$ & $d-\varepsilon, d-\varepsilon$ \\
\hline
\end{tabular}


Table 6.4 Pay-offs to depositors if $\mathrm{d} \leq \mathrm{L}<2 \mathrm{~d}$ and $\mathrm{e} \geq 0$

\begin{tabular}{l|l|l}
\hline$D_{1}, D_{2}$ & $K_{2}$ & $R_{2}$ \\
\hline$K_{1}$ & d, d & $d, d-\varepsilon$ \\
\hline$R_{1}$ & $d-\varepsilon, d$ & $L / 2-\varepsilon, L / 2-\varepsilon$, \\
\hline
\end{tabular}

Table 6.5 Bank's balance sheet at the moment of default in the non-equilibrium run scenario $\mathrm{L}=$ $\Lambda+(1-\Lambda)(1-\mathrm{h})$

\begin{tabular}{|l|r|lr|}
\hline \multicolumn{4}{|c|}{ Bank } \\
\hline Liquid assets (sold) & 0 & Short-term debt 1 & $\mathrm{~d}-\mathrm{L} / 2$ \\
\hline Illiquid assets (pledged) & $1-\Lambda$ & Short-term debt 2 & $\mathrm{~d}-\mathrm{L} / 2$ \\
\hline & & Long-term debt & $1-\mathrm{e}-2 \mathrm{~d}$ \\
& & Equity & $\mathrm{e}$ \\
Total assets & $(1-\Lambda)$ & Total liabilities & $(1-\mathrm{h})(1-\Lambda)$ \\
\hline
\end{tabular}

Table 6.6 Pay-offs to depositors if $\mathrm{L}<\mathrm{d}$ and $\mathrm{e} \geq 0$

\begin{tabular}{l|l|l}
\hline$D_{1}, D_{2}$ & $K_{2}$ & $R_{2}$ \\
\hline$K_{1}$ & d, d & $0, L-\varepsilon$ \\
\hline$R_{1}$ & $L-\varepsilon, 0$ & $L / 2-\varepsilon, L / 2-\varepsilon$ \\
\hline
\end{tabular}

All deposits that could not be withdrawn, as well as all long-term claims and equity are lost because following our assumption regarding collateral liquidation by the central bank, the liquidation of the pledged assets will suffice to just repay central-bank funding.

(3) Table 6.6 shows pay-offs if liquidity is insufficient to pay out even one depositor, but equity is still non-negative. Two equilibriums emerge: one in with both depositors stay with their deposits, and one, inferior, in which they both run, causing default and the related losses.

Running is now an equilibrium because if the other depositor runs, and you don't, then you end up with zero value as the liquidation of the bank will lead to a zero recovery ratio. In contrast, if you are the one who runs and the other doesn't, then you recover $\mathrm{L}>0$, while if you also do not run, you recover only $\mathrm{L} / 2$.

\subsubsection{Negative Equity}

If equity is negative, the bank will eventually be closed and its assets will be liquidated by the regulator. By definition, the recover ratio $r$ with negative equity will be $0<\mathrm{r}$ $<1$ of their claims, while $1-r$ will be the loss-given default. Depositors can try to withdraw their deposits without losses before liquidation and the more a depositor 
withdraws, the more the losses will be dumped on the other creditors who will have a higher loss-given-default. As the game is symmetric, there will be a unique run equilibrium. We call $r=1+\mathrm{e}($ with $\mathrm{e}<0)$ the recovery ratio in the absence of runs, i.e. the recovery ratio that would be equally applied to short-term and long-term creditors in this case. We call r' the recovery ratio for the remaining creditors if only one depositor runs, and r" the one if both depositors run. Clearly, $0 \leq r^{\prime \prime} \leq r ' \leq r \leq$ 1 .

(4) Table 6.7 shows pay-off if liquidity is enough to pay out both depositors:

- If no depositor runs, both depositors will recover a share $r$ of their deposit after liquidation.

- If one depositor runs, one will completely recover her deposit and the other deposit a share r' after liquidation.

- If both run (equilibrium solution), both will recover all their deposits, all losses will fall on the long-term creditor.

(5) Table 6.8 shows pay-offs if liquidity is enough to pay only one depositor:

- If none run: they will recover a share $r$ of their deposit after liquidation, which is exactly the same as in case 4

- If only one runs: she will recover her full deposit, while the other depositor will recover a share r' after liquidation

- If both run: there is not enough liquidity to withdraw all deposits. They will withdraw an amount equal to the whole disposable liquidity and divide them proportionally on each's share of the total deposit. The long-term creditor will lose all his capital, as we assumed that the sale of the bank's asset will not provide any further amount beyond what is provided by the central bank

(6) Finally, Table 6.9 shows the pay-offs if liquidity is not enough even for paying out a single depositor, the depositor that runs will be able to recover at least part of its credit without haircut, both r' and r" are equal to zero.

Table 6.7 Pay-offs to depositors if $\mathrm{L} \geq 2 \mathrm{~d}$ and $\mathrm{e}<0$

\begin{tabular}{l|l|l}
\hline$D_{1}, D_{2}$ & $K_{2}$ & $R_{2}$ \\
\hline$K_{1}$ & $r^{d}, r d$ & $r^{\prime} d-\varepsilon, d-\varepsilon$ \\
\hline$R_{1}$ & $d-\varepsilon, r^{\prime} d-\varepsilon$ & $d-\varepsilon, d-\varepsilon$ \\
\hline
\end{tabular}

Table 6.8 Pay-offs to depositors if $\mathrm{d} \leq \mathrm{L}<2 \mathrm{~d}$ and $\mathrm{e}<0$

\begin{tabular}{l|l|l}
\hline$D_{1}, D_{2}$ & $K_{2}$ & $R_{2}$ \\
\hline$K_{1}$ & rd, rd & r'd, d $-\varepsilon$ \\
\hline$R_{1}$ & $d-\varepsilon, r^{\prime} d$ & $L / 2-\varepsilon, L / 2-\varepsilon$ \\
\hline
\end{tabular}


Table 6.9 Pay-offs to depositors if $\mathrm{L}<\mathrm{d}$ and $\mathrm{e}<0$

\begin{tabular}{l|l|l}
\hline$D_{1}, D_{2}$ & $K_{2}$ & $R_{2}$ \\
\hline$K_{1}$ & rd, rd & $0, L-\varepsilon$ \\
\hline$R_{1}$ & $L-\varepsilon, 0$ & $\mathbf{L} / \mathbf{2}-\varepsilon, \mathbf{L} / \mathbf{2}-\varepsilon$ \\
\hline
\end{tabular}

Table 6.10 Utility of depositor 1 depending on own and depositor 2 's decisions: $\mathrm{U}_{1}\left(\mathrm{D}_{1} \mathrm{D}_{1}\right)$

\begin{tabular}{|c|c|c|c|c|c|c|c|}
\hline & & (1) & (2) & (3) & (4) & (5) & (6) \\
\hline & & \multicolumn{5}{|c|}{$e \geq 0$} & \multicolumn{3}{|c|}{$e<0$} \\
\hline $\mathrm{D}_{1}$ & $\mathrm{D}_{2}$ & $L \geq 2 d$ & $2 d>L \geq d$ & $L<d$ & $L \geq 2 d$ & $2 d>L \geq d$ & $L<d$ \\
\hline $\mathrm{K}_{1}$ & $\mathrm{~K}_{2}$ & $\mathbf{d}$ & $\mathbf{d}$ & $\mathbf{d}$ & $\mathrm{Rd}$ & $\mathrm{rd}$ & $\mathrm{rd}$ \\
\hline $\mathrm{K}_{1}$ & $\mathrm{R}_{2}$ & $\mathrm{~d}$ & $\mathrm{~d}$ & 0 & $\mathrm{r}$ 'd & $\mathrm{r} ' \mathrm{~d}$ & $\mathrm{r}$ 'd $=0$ \\
\hline $\mathrm{R}_{1}$ & $\mathrm{~K}_{2}$ & $\mathbf{d}-\boldsymbol{\varepsilon}$ & $\mathbf{d}-\boldsymbol{\varepsilon}$ & $\mathbf{L}-\boldsymbol{\varepsilon}$ & $\mathrm{d}-\varepsilon$ & $\mathrm{d}-\varepsilon$ & $\mathrm{L}-\varepsilon$ \\
\hline $\mathrm{R}_{1}$ & $\mathrm{R}_{2}$ & $\mathrm{~d}-\varepsilon$ & $\mathrm{L} / 2-\varepsilon$ & $\mathbf{L} / \mathbf{2}-\boldsymbol{\varepsilon}$ & $\mathbf{d}-\boldsymbol{\varepsilon}$ & $\mathbf{L} / \mathbf{2}-\boldsymbol{\varepsilon}$ & $\mathbf{L} / \mathbf{2}-\boldsymbol{\varepsilon}$ \\
\hline
\end{tabular}

In Table 6.10 we summarise the results showing the payoffs for player 1 . The shaded area indicates where the bank is liquidated. The areas with bold larger font are the equilibrium solutions of the run game.

\subsubsection{Central Bank Collateral Easing to Restore Financial Stability in a Financial Crisis}

Asset liquidity (as captured by the parameter $\Lambda$ ) and asset values can change over time, and also the central bank may change haircuts over time. For example, Fig. 6.3 (from Dötz and Weth 2019, 12) illustrates how asset liquidity fluctuates over time. Moreover, asset values can change, which is reflected in a change of equity. For example, if initial equity is 0.2 and total assets 1 , then a decline of asset values by more than $20 \%$ depletes equity and therefore pushes the bank into a single run equilibrium. Asset value deterioration also leads to a deterioration of the liquidity condition, as it leads to a shrinkage of liquidity relative to short term debt.

To what extent can the collateral framework of the central bank as captured by $\mathbf{h}$ make a difference for funding stability? First, obviously $h$ does not impact on solvency. Therefore, whenever e $<0$ we are unavoidably in the case of the single bank run equilibrium. Central banks should not combat financial instability due to negative equity with collateral policies. However, h can make the difference for meeting the liquidity condition. We can calculate the maximum haircut compatible with a single no-run equilibrium from the condition of sufficient liquidity. Therefore, it is easy to show that decreases of $\mathrm{h}$ can compensate both unexpected asset value declines and a 
drop of the share of liquid assets in terms of restoring the condition $\mathrm{L}>\mathrm{d}$, assuming that equity remained positive.

\section{Cheapest stable funding structure}

If the bank does not fear a deterioration of asset values or a decline of the share of liquid assets, it will choose the cheapest liability structure that is just supporting a single no-run equilibrium. If cost of equity is higher than the cost of long-term debt, the bank will, in the model above, however not issue any equity and achieve its competitive stable funding structure only through sufficient long-term funding. This is the limitation of the simplest model setting: it does not allow modelling equity as a safeguard against fire-sale losses, and therefore does not contribute to a better understanding of the full liability structure including equity. Consider the following example: if $\Lambda=0.3$ and $\mathrm{h}=0.8$ then the funding structure maximising short term deposits is the one in which $\mathrm{d}=0.44$, i.e. $\mathrm{t}+\mathrm{e}=0.12$ and $\mathrm{e} \geq 0$. For any $\left(\mathrm{i}_{\mathrm{t}}, \mathrm{i}_{\mathrm{e}}\right)$ with $\mathrm{i}_{\mathrm{t}}<\mathrm{i}_{\mathrm{e}}$, the cheapest stable funding structure will be $\mathrm{e}=0, \mathrm{~d}=0.88$, and $\mathrm{t}=0.12$.

\subsubsection{Collateral Policies as Monetary Policies at the ZLB}

\section{Broadening the collateral set in a liquidity crisis may be a key monetary policy} measure, in particular when conventional monetary policy has hit the zero lower bound. The simple bank- run model above allowed us to show that when asset liquidity deteriorates, then banks need to move to a more expensive bank liability structure. If they do so quickly enough, the bank-run equilibrium may not materialize. But a more expensive capital structure means that the spread between the short-term risk-free interest rate (controlled by the central bank) and the actual bank financing costs, and thus bank lending rates, increase. The central bank could maintain financial conditions unchanged by lowering the short-term risk-free interest rate. This is however not an option if the zero lower bound has been reached. The central bank could therefore broaden its collateral framework so as to make the old, cheap bank liability structure stable again.

We illustrate the last point further with the bank balance sheet in Table 6.11.

This bank has stable short term funding if $L=\Lambda+(1-\Lambda)(1-h) \geq d / 2 \Rightarrow d^{*}=1$ $-\mathrm{h}+\mathrm{h} \Lambda$, with d obviously capped at 1 . Assume that the financial conditions ("FC") are equal to bank lending rates, and these are equal to the average funding costs of the

Table 6.11 Effectiveness of collateral policies at the zero lower bound

\begin{tabular}{|lr|l|r|}
\hline \multicolumn{3}{|c|}{ Bank } & $\mathrm{d} / 2$ \\
\hline Liquid assets & \multicolumn{1}{|c|}{$\Lambda$} & Short term debt 1 & $\mathrm{d} / 2$ \\
\hline Illiquid assets & $1-\Lambda$ & Short term debt 2 & $1-\mathrm{d}$ \\
\hline Total assets & & Long term debt & 1 \\
\hline
\end{tabular}


banks, as banks would be perfectly efficient, i.e. would not have any administrative costs and be within a competitive sector. Also assume that the funding costs of shortterm deposits is equal to $i$, the risk-free short-term interest rate, which is the monetary policy interest rate set by the central bank. Assume that the cost of long-term funding is equal to the sum of the short-term risk-free lending rate, $\mathrm{i}$, plus the term premium, $\omega$. Therefore: $\mathrm{FC}=\mathrm{id}+(\mathrm{i}+\omega)(1-\mathrm{d})=\mathrm{i}+\omega-\omega \mathrm{d}$.

By substituting the highest possible share of short-term deposits which ensures stable funding, we obtain ${ }^{1}: \mathrm{FC}=\mathrm{i}+\omega-\omega 2(1-\mathrm{h}+\mathrm{h} \Lambda) \Leftrightarrow \mathrm{FC}=\mathrm{i}+\omega(2 \mathrm{~h}(1-\Lambda)$ - 1). In words: financial conditions tighten (funding costs increase) with (i) shortterm risk-free interest rates, (ii) the equity risk premium, (iii) the haircuts imposed by the central bank, (iv) the share of illiquid assets. Therefore, when the zero lower bound is reached for conventional monetary policy, then haircuts can contribute to achieve the adequate monetary policy (i.e. the adequate financial conditions), and a decrease in haircuts can be a measure necessary to compensate for an increase of the equity risk premium or a deterioration of asset liquidity. Of course, such a lowering of haircuts for monetary policy purposes should not imply that the role of haircuts to protect the central bank from losses should be forgotten, i.e. the central bank will face a trade-off between monetary policy objectives and risk objectives.

\subsubsection{The Model with Continuous Asset Liquidity}

In this model variant (Bindseil 2013), one assumes that (i) assets are continuous in terms of liquidity properties, that (ii) they are equally ranked from both the fire-sale loss and central bank haircut perspectives, and that (iii) both haircuts and fire-sale discounts have the functional form across the assets of a power function, i.e. haircuts are $h(x)=x^{\delta}$ and marginal fire sale losses are $f(x)=x^{\theta}$ with $\delta>0$ and $\theta>0$, i.e. $\theta$ summarises the liquidation cost function and $\delta$ the central bank haircut function. This continuous approach to asset liquidity and central bank haircuts has a number of advantages: (i) it allows us to differentiate between the roles of equity and long-term debt; (ii) it is more realistic than the assumptions taken on assets so far; (iii) the power function is tractable in the context of our model.

Consider first the case when the central bank does not at all act as lender of last resort, i.e. the only source of liquidity generation in the case of a run is to fire-sell assets. If a certain share $\mathrm{x}$ of the bank's assets has to be sold, then the fire-sale discounts will have to be booked as a loss and reduce equity. Assuming that the bank starts with the most liquid assets and sells a share $\mathrm{x}$ of total asset, the total fire sale loss will be:

$$
F(x, \theta)=\int_{s=0}^{x} s^{\theta} d s=\frac{x^{\theta+1}}{\theta+1}
$$

\footnotetext{
${ }^{1}$ Note that the multiplier of $\omega$ will be positive for the assumption that $2 \mathrm{~d}^{*}<1$. Indeed $2 \mathrm{~d}^{*}=2(1$ $-\mathrm{h}+\mathrm{h} \Lambda)<1 \Rightarrow-2 \mathrm{~h}(1-\Lambda)<-1 \Rightarrow \mathrm{h}(1-\Lambda)>1 / 2$.
} 
As mentioned in Chap. 5, empirical estimates of default costs in the corporate finance literature vary between $10 \%$ and $44 \%$. This cost can be interpreted as the liquidation cost of assets, captured in the parameter $\theta$. Liquidation of all assets will lead to a damage of $\mathrm{F}(1)=1 /(1+\theta)$, and sales proceeds (cash generated) will be $1-\mathrm{F}(1)=\theta /(1+\theta)$. Consequently, $\theta$ can be calculated as $\theta=(1-\mathrm{F}(1)) / \mathrm{F}(1)$. If default cost is $10 \%$, this would mean that $\theta=9$, and if default cost is $44 \%$, then $\theta$ $=1.27$. For a value of default costs in the middle of the empirical estimates of say $25 \%$, one obtains $\theta=3$.

In Fig. 6.2 below, we illustrate this approach by showing the distribution between liquidity generation and asset fire-sale losses under the assumption of a power function of fire-sale costs and ranked asset from the most to the least liquid, for the range of the empirical estimates of costs of default, i.e. for $10 \%$ (implying $\theta=9$ ) and $44 \%$ (implying $\theta=1.25$ ). Moreover, we show the power function to replicate the estimated recovery ratio in the case of the Lehman Brothers of $28 \%$, i.e. default costs of $72 \%$ under the assumption that before default, Lehman had zero equity (Fleming and Sarkar 2014a, b).

That asset liquidity is continuous, and that it fluctuates over time, has been described empirically in the finance literature, such as recently in Dötz and Weth (2019), who also argue that liquidation will be carried out in a liquidity pecking order style and that marginal liquidation costs should be expected to increase in redemptions. They construct a sample of corporate bond fund asset liquidity data covering the 80 months before June 2016, referring to around 700 thousand security holdings positions. Price and liquidity information are added to each such position. The liquidity measure consists in monthly averages derived from daily bid-ask spreads. Figure 6.3 shows continuous portfolio liquidity, put at any moment in time into a "liquidity pecking order" (i.e. securities ranked from the most to the least liquid). Obviously, the least liquid assets held by a corporate bond fund will still be more liquid than many other bank assets (e.g. loan portfolios). Still, it nicely illustrates the idea of continuous asset liquidity and the changes of asset liquidity over time.

Assume that in the case of a bank run, the bank does whatever it takes in terms of asset liquidation to avoid illiquidity induced default. The total amount of liquidity that the bank can generate through asset fire sales is $\theta /(\theta+1)$. Therefore, illiquidity

$F(1)=10 \%$ (implying $\theta=9$ )

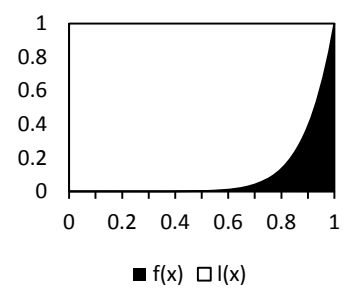

$F(1)=44 \%$ (implying $\theta=1.25$ ):

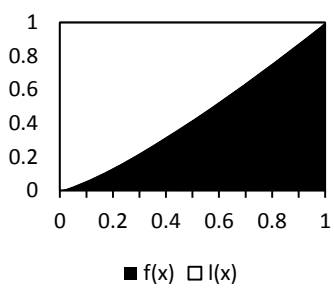

$F(1)=72 \%$ (implying $\theta=0.4$ )

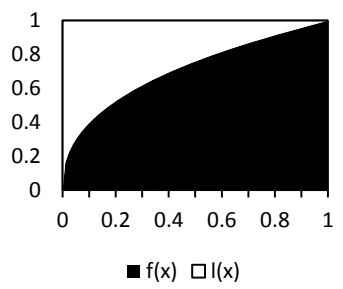

Fig. 6.2 Three representations of fire sale losses and liquidity generation assuming that marginal fire sale losses $\mathrm{f}(\mathrm{x})$ are a power function with exponent theta 


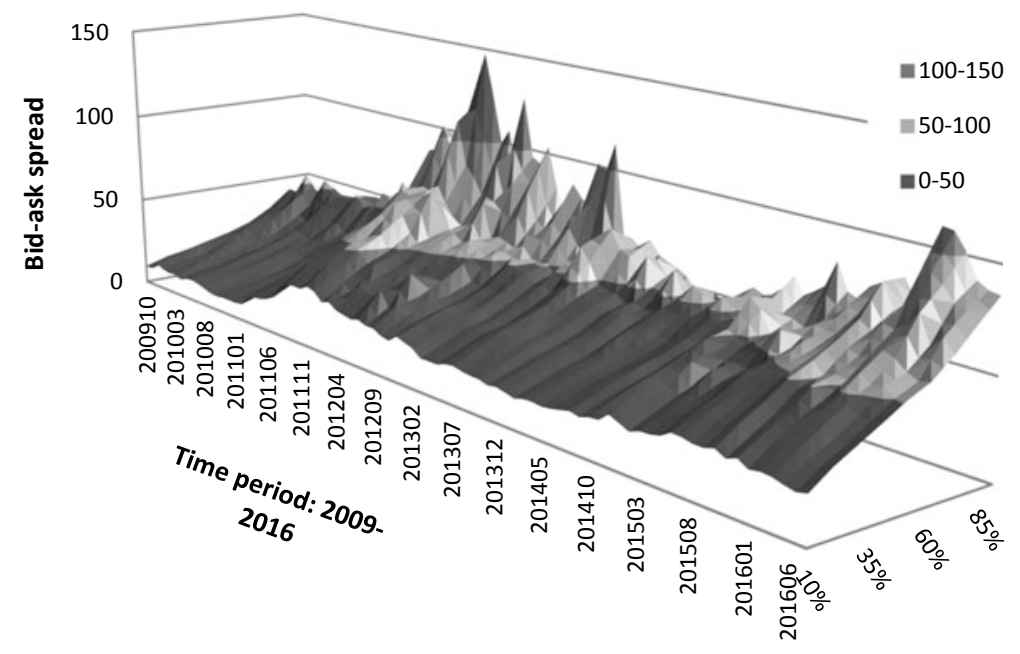

Fig. 6.3 Liquidity structure of corporate bond funds, according to Dötz and Weth $(2019,12)$

induced default will materialise only if deposit withdrawals eventually exceed this amount. Two default triggering events need to be considered. Indeed, even if the bank has survived a liquidity withdrawal, it may afterwards be assessed as insolvent and thus be liquidated at the request of the bank supervisor. As noted above, for a given liquidity withdrawal $\mathrm{x}$, the fire-sale related loss is $\mathrm{x}^{\theta+1} /(\theta+1)$ (Fig. 6.3).

Default due to insolvency occurs if this loss exceeds initial equity, i.e. $\mathrm{e}<\mathrm{x}^{\theta+1} /(\theta$ $+1)^{2}$ It can be shown (see e.g. Bindseil 2013, proposition 2) that a single no-run equilibrium exists if and only if (and assuming again the bank liability structure shown at the beginning of Sect. 6.5) both a liquidity and a solvency condition are fulfilled:

$$
\theta /(\theta+1) \geq \mathrm{d} \text { and } \mathrm{e} \geq \mathrm{d}^{\theta+1} /(\theta+1) .
$$

The liquidity condition is similar to the discrete case: to ensure financial stability in the case of absence of central bank credit, the liquidity generating capacity of the bank needs to correspond at least to the deposits of one of the two depositors. The solvency condition expresses an aspect that could not be captured in the discrete case: the financial damage suffered by generating through fire sales the liquidity needed to pay out one of the two depositors must not exceed the bank's equity.

What is the cheapest sustainable liability structure in this model? For given $\theta$, competing banks will always go to the limit in terms of the cheapest possible liability structure as determined by the conditions in the strategic depositor game, such that the no-run equilibrium is still maintained as an SNNR equilibrium. Assume that the

\footnotetext{
${ }^{2}$ Note that it is assumed that equity is never sufficient to absorb the losses resulting from a bank default, i.e. it is assumed that $\mathrm{e} \leq 1 /(\theta+1)$. Of course, one could also calculate through the opposite case, but it is omitted here as it does not seem to match reality.
} 
cost of remuneration of the three asset types are $r_{e}$ for equity, $r_{t}$ for term funding, and 0 for short term deposits. Also assume that $r_{e}>r_{t}>0$. In this setting what will the composition of the banks' liabilities be? The objective of choosing a liability composition will be to minimize the average overall remuneration rate subject to maintaining a stable short-term funding basis. The two minimum conditions to be fulfilled are $\theta /(1+\theta)=\mathrm{d}$ and $\mathrm{e}=\mathrm{d}^{(1+\theta)} /(1+\theta)$. These conditions can be solved for a unique optimum $\mathrm{e}^{*}, \mathrm{~d}^{*}$, and hence also for the average necessary remuneration rate of bank liabilities $\mathrm{t}^{*}$ being $\mathrm{r}_{\mathrm{t}}+\mathrm{e}^{*} \mathrm{r}_{\mathrm{e}}$.

\section{If the central bank offers collateralised credit}

Now consider the case in which also the pledging of collateral with the central bank is possible. To obtain outcomes in which the banks rely both on fire sales and haircuts in their liquidity stress strategy, we obviously need $\delta>\theta$ (otherwise it is always superior to only pledge and never to fire-sale). It can be shown in the nontrivial case that the bank's liquidity stress strategy will always foresee the share $\mathrm{z}$ of most liquid assets to be fire-sold, while the rest, the $1-\mathrm{z}$ less liquid assets, will be pledged with the central bank. The condition for an SNNR is provided in proposition 5 of Bindseil (2013):

Let $z$ in $[0,1]$ determine which share of its assets is foreseen by the bank to be used for fire sales (i.e. the less liquid share $1-z$ of assets are foreseen for pledging with the central bank). Let $F=F(z)$ be the fire-sale losses from fire selling the $z$ most liquid assets and let $L=L(z)$ be the total liquidity generated from fire-selling the most liquid assets $z$ and from pledging the least liquid assets $(1-z)$. Then a single no run equilibrium exists if and only if

$$
\exists z \in[0,1]: L=L(z)=\frac{\delta}{\delta+1}+\frac{z^{\delta+1}}{\delta+1}-\frac{z^{(\theta+1)}}{\theta+1} \geq d
$$

and

$$
F=F(z)=\frac{z^{(\theta+1)}}{\theta+1} \leq e
$$

In contrast to the discrete model variant, this variant allows us to explain the full capital structure, including the distinction between long-term debt and equity, and the roles of these two funding sources can be shown to depend on the relative cost of the two and the relative size of $\delta$ compared to $\theta$.

The model and its solution are illustrated in Fig. 6.4. The vertical line z separates the liquidity-ranked asset space into the part that will be fire-sold (assets on the left of $\mathrm{z}$, i.e. most liquid assets) and the part that will be pledged (assets on the right of $\mathrm{z}$, i.e. least liquid assets). The bank foresees in its liquidity stress strategy to fire-sale the assets $[0, \mathrm{z}]$ and to incur fire-sale losses of $\mathrm{F}$, and generate liquidity through fire sales equal to $\mathrm{L}_{1}$. Moreover, in this strategy the bank pledges the assets $[\mathrm{z}, 1]$ and generates through this liquidity equal to $\mathrm{L}_{2}$. Therefore, total liquidity generated (which must 

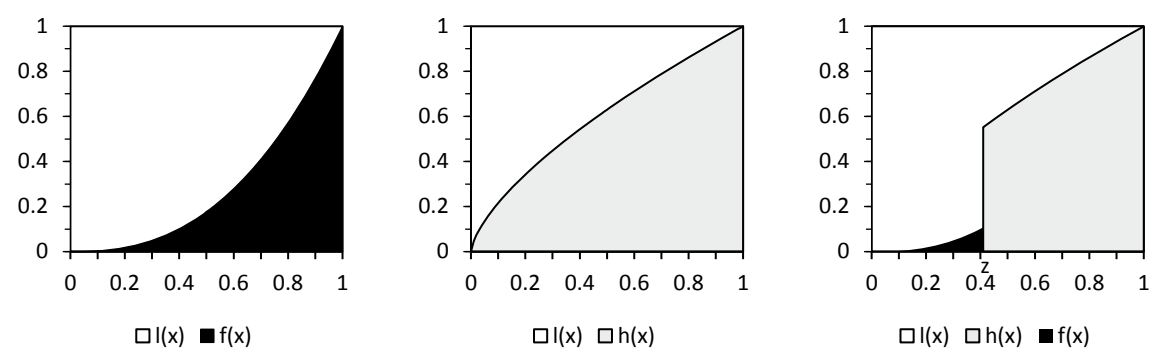

Fig. 6.4 Liquidity generation and fire sales in a model of continuous asset liquidity. Left: using fire sales, centre: using pledging at the Central Bank, right: using box

Table 6.12 Bank financed only by short term debt and equity

\begin{tabular}{|c|c|c|c|}
\hline \multicolumn{4}{|c|}{ Bank A } \\
\hline \multirow[t]{3}{*}{ Assets } & 1 & Depositor 1 & $\mathrm{~d}$ \\
\hline & & Depositor 2 & $\mathrm{~d}$ \\
\hline & & Equity & $1-2 d$ \\
\hline Total & 1 & Total & 1 \\
\hline
\end{tabular}

at least be equal to the deposits of one depositor) is $\mathrm{L}_{1}+\mathrm{L}_{2}$ and total fire-sale losses are $\mathrm{F}$ (which must not exceed equity e).

To calculate the relevant surfaces as illustrated in Fig. 6.4, we only need to apply that the integral of $x^{a}$ in $[0, z]$ is equal to $z^{(a+1)} /(a+1)$. $L_{1}$ is the surface above the fire-sale loss function up to $\mathrm{z}$ (the liquidity generated from fire sales); $F$ is the surface below the fire-sale loss function up to $\mathrm{z}$ (the losses generated from the sales), and $\mathrm{L}_{2}$ is the surface above the haircut function between $\mathrm{z}$ and 1 (the liquidity generated by pledging assets).

$$
L_{1}=z-B=z-\frac{z^{\theta+1}}{\theta+1} F=\frac{z^{\theta+1}}{\theta+1} L_{2}=1-\frac{1}{\delta+1}-\left(z-\frac{z^{\delta+1}}{\delta+1}\right)
$$

Example: assume that banks' liabilities consist only of equity and short-term debt, such as in Table 6.12.

Also assume that initially $\theta=1.4, \delta=0.5$ and $\mathrm{e}=0.2$ so that each depositor has deposits of 0.4 . One can now calculate that with $\mathrm{z}=0.5$, one obtains liquidity generating power $\mathrm{L}=0.49$ and associated fire-sale losses $\mathrm{F}=0.08$ (this is easily done by putting the formulas of the surfaces $\mathrm{L}_{1}, \mathrm{~F}, \mathrm{~L}_{2}$ from the chart above into Excel). This allows for a single no-run funding equilibrium. 


\subsection{Conclusions}

The following five key conclusions can be drawn from the simple bank run model (and taking various simplifying model assumption as described, including that banks and depositors have the same perfect information on asset values, asset liquidity, and bank liability composition): First, both asset value and asset liquidity deterioration can trigger a run. Second, insufficient liquidity leads to multiple equilibria, while negative equity always implies a run. Therefore, the LOLR (i.e. captured in this simple setting by central bank collateral haircuts) will never stop a run if equity is negative. However, LOLR action can restore a single no-run equilibrium when only an asset liquidity deterioration and/or an asset value deterioration occurs, as long as equity remains positive. Third, tightening collateral rules can destabilize banks by pushing them into the multiple equilibrium case. Fourth, if an asset liquidity deterioration pushes banks into the multiple equilibrium case without the run equilibrium materializing, banks will be incentivized to adjust their capital structure so as to restore the single no-run equilibrium case. This typically leads to a more expensive capital structure, i.e. to more expensive bank intermediation and hence, everything else equal, a tightening of monetary and financial conditions. If monetary policy has reached the zero lower bound, increasing collateral availability can be an effective monetary policy tool. Fifth, if banks through competition and myopic behaviour tend to converge to the cheapest sustainable liability structure, then very small shocks on asset value and asset liquidity can destroy funding stability. It may therefore be useful to impose liquidity regulation on banks.

Open Access This chapter is licensed under the terms of the Creative Commons Attribution 4.0 International License (http://creativecommons.org/licenses/by/4.0/), which permits use, sharing, adaptation, distribution and reproduction in any medium or format, as long as you give appropriate credit to the original author(s) and the source, provide a link to the Creative Commons license and indicate if changes were made.

The images or other third party material in this chapter are included in the chapter's Creative Commons license, unless indicated otherwise in a credit line to the material. If material is not included in the chapter's Creative Commons license and your intended use is not permitted by statutory regulation or exceeds the permitted use, you will need to obtain permission directly from the copyright holder.

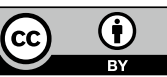

